much was obvious; but the task of locating the source of this air stream was a complex problem, with the normal difficulties of field-research increased by the extreme conditions of the locality, and the limited daylight. We decided that the only certain method of fixing the position of the source would be by establishing the relative situation of the lowest temperature in the basin at sea-level, and tracing the source from there. We accomplished this by circumnavigating the basin, measuring the temperature at frequent intervals. Eventually we succeeded in compiling sufficient reliable figures to plot isotherrns for the region. Simultaneously with these journeys, we ascended the slopes of the mountains rising from the basin, in order to determine the vertical extent of the climatic zone. The inversions recorded on all occasions showed the temperature at $1,000 \mathrm{ft}$. to be $10^{\circ} \mathrm{F}$. higher than that at sea-level. The curve of this temperature gradient indicated that the rise took place mainly in the upper $500 \mathrm{ft}$.

All the temperature-recording journeys proved beyond doubt that the very lowest temperatures occurred at a point just south of the fjord-ice at the base of a wide defile leading to a glacier-filled $\mathrm{cwm}$, at an altitude of $1,500 \mathrm{ft}$. As the mountain walls on either side of the defile reached heights exceeding $2,000 \mathrm{ft}$., it was safe to assume that the glacier cwm and the defile itself were both free from wind, and therefore unlikely to be affected by cold air currents from the interior of the peninsula. It followed from this that the source of the cold air stream was the glacier.

The sequence of events from the time that a parcel of cold air accumulates near the snout of the glacier can now be traced. By virtue of its greater density, the glacier-cooled air would push itself under any comparatively warm air in the vicinity, and flow down the subsidiary valley formed by the rock walls of the defile. On reaching sea-level, it would attain a state of almost complete stability, that is to say, there would be little or no convection within the air itself, or heat exchange between the snow cover of the basin and the air. In relation to the latter, it should be remembered that, for a climatologist working during the Aretic night, the polar nocturnal constant relieves him of problems of solar or terrestrial radiation.

Having reached the valley floor, the parcel of air would flow over the surface of the fjord-ice toward the open water in the north. As it approached the warmer air near the water, it would cease to be a level stratum, and become instead a wedge of air, behaving in exactly the same manner as a macroclimatic cold front. The water in the fjord was always $20^{\circ} \mathrm{F}$. warmer than the air from the south, and therefore a fog layer 5 metres thick and 3 metres above the surface of the water would form at the point of occlusion.

Our conclusion from the above was that, during winter months when the moderating factors of radiation and reflexion were set at nought by the absence of the sun, the local climate of the mountain basin was entirely dependent upon the glacier at the southern extremity of the fjord valley; also, that this modification of macroclimate was quite out of proportion to the relatively small area occupied by the glacier.

The significance of such an area is obvious when one considers the difficulties of studying the relationship between glaciers and climate in the lower latitudes of Europe, where the climatologist has to account for an extremely wide diurnal temperaturerange and other complicating agents, such as noc- turnal heat exchange, ablation of the snow, and erratic winds. All these disturbing influences are removed during the period after the winter solstice, and it is possible to obtain almost perfect continuity in climatic observations until the return of the sun in February. So it may be said that, in the glaciated areas of Arctic Scandinavia, the climatologist has a virgin field, easily accessible, and abounding in possibilities for winter research on a smaller, and consequently more accurate, scale than is at present possible in Austria or Switzerland.

\section{AUTOMATION IN THE SOVIET UNION}

71

HE U.S.S.R. claims to have achieved the automatic factory, but little detail is available; more definite information, at least indicating some of the lines along which research in this field is proceeding or is contemplated in the Soviet Union, may possibly be found in reports of two recent conferences : one on the modern theory of machines, and the other on the progress of automation in the consumer goods industries-mainly food and textiles.

The first of these, reported in Vestnik Akad. Nauk SSSR, No. 12, 1954, is by I. I. Artobolevskii and co-workers, and is chiefly devoted to the paper they themselves read at the conference, with a few brief notes on some of the other papers. The meeting was organized by the Institute of Machine Construction (affiliated to the Academy of Sciences of the U.S.S.R.), and was an attempt to strengthen the scientific foundations of the machine construction industry.

Artobolevskii's paper emphasizes the importance of the theory of machines and mechanisms, especially in relation to the growing demands of automation. Discussing first of all the general theory, he thinks this is fully developed only in the case of prime movers, and as yet very imperfectly in other directions. A main factor to-day is the greatly increased speed of operation and general efficiency, the effect of which still requires close study. But the most important direction for the development of modern machine design is that of automatizing and mechanizing technological or industrial operations. In recent years in the Soviet Union many types of automatic machine have been evolved. Automatic and continuous production lines have been widely adopted. Most of the heavy and laborious operations in mining, metallurgical, building and other industries have been mechanized. Soviet scientists have discussed many fundamental questions relating to automatic machines and mechanisms. More especially they have outlined the general theory of the cyclogram automatics, analysed problems of regulation and control, suggested means and methods for design of individual types of mechanisms, and so forth.

Many difficulties in the theory of automatic machines still await discussion and solution. Among the fundamentals, for example, are the dynamics of free-flowing bodies or material to be mechanically ground, screened and conveyed; the dynamics of bending or flexing of fibres and threads in textile, cable-making and similar machines; the hydrodynamics of viscous liquids to be treated in separators, centrifugal or other; the aerodynamics of air currents in wind motors and the like, including the various kinds of pneumatic mechanisms. These 
matters and many others demand specialists in mechanics, physics and chemistry, and their close co-operation. The author also refers to the need for rationalizing the form or geometry of the working organs and tools in a wide range of varied operations. A valid theory of working processes and operation should form the basis of generalizing methods of tool-form design.

A study of power and kinetic characteristics is also essential, and needs carefully planned experiment, with the development of methods and instruments for recording movements, speeds, accelerations, forces involved, and capacities. An important part here will be played by the new electronic, acoustic and electromagnetic devices, radioactive isotopes, the piezo-effect and other means now being applied. Calculation and design of automatic machine units involves furthermore a precise knowledge of their "kinetic layout (scheme) in principle", and more specifically their operational cycles and relations.

The cyclogram theory requires further development, since the determination of one or the other working cycle depends not only on the particular process or function, but also on speeds and accelerations of the several units, and the forces actuating these. From analysis of all these characteristics a general cyclogram may be constructed, conforming to the optimum performance of the machine with minimum expenditure of power on unproductive wastes or losses and maximum equalization of torque on the driving shafts.

The author proceeds to analyse the various mechanisms taking part in the operations : driving, transmission, directing, controlling, speed variation, stopping, etc. Special reference is made here to the design of cam mechanisms of the three-dimensional type, with the complaint that, in their kinetic and other aspects, theory has been little developed in the Soviet Union. Much the same applies to lever mechanisms, to non-stepped drives-so important in automatic machines-and to other units. Research in hand in some institutes in these and some other fields must be both intensified and extended.

Some of the fundamental differences between automatic and non- or semi-automatic machines are noted. In the former, a control unit called a 'datchik' appears to be of primary importance. It has been variously designated by British engineers as a booster, a pickup, etc. By means of suitable 'datchiks', variations in such parameters as speed, pressure, temperature, volume or density, are transmitted to the appropriate controls. In general terms, the author refers to certain lines of progress in the Soviet Union in the matter of controls not only for solids, but also for other forms of product, in statistical controls and computers, in programming, and so forth.

Other matters discussed also in general terms include the effect of clearance or play in kinetic couples, resilience, forces of dry and lubricated friction-requiring new methods of study and experiment-and temperatures. The hydrodynamic theory of friction is said to be well developed on the mathematical side, but less so on the experimental. The author considers that one of the most important parts of modern machine theory relates to machines in series or aggregates. Hitherto it has been developed quite separately for prime movers on one hand and the operative machines on the other; but under modern conditions the boundary line between these two classes is sometimes quite obliterated. It is now essential to regard the aggregate as one entity.
Somewhat more definite, but still largely in general terms, is an article in an earlier issue of Vestnik $A N$ (No. 8, 1954) by N. N. Shumilovskii on some problems of automation in the Russian consumer goods industries, primarily as a means of increasing output of these goods and removing some of the bias in favour of heavy industries that has lately marked Soviet economy. His article is based on a recent conference sponsored by the Institute of Automatics and Telemechanies in collaboration with Ministry of Consumer Goods Production. Some of the fundamental requirements for conversion to complete automation and the creation of the automatic factory are indicated. These include close examination of particular cases of complete automation, preferably of a more or less standard type, so that the experience gained can be widely applied.

Some of these basic problems were discussed in a paper by V. A. Trapeznikov, with a certain amount of detail in other papers read at the conference. By way of example, conditions in the cotton industry were considered, in its different divisions : spinning, weaving and finishing. In the first there is a continuous production line, with almost complete mechanization; but there is scope for more automation. In weaving, automatic machines are mainly used, but certain difficulties still remain : maintaining constant $(a)$ tensions of thread at various stages, (b) temperature, level and viscosity of sizes, and $(c)$ moisture content of yarn ; $(d)$ automatic warning of flaws, and stoppage for breaks or completion of bale, or wrong patterns, etc. Various manual operations remain to be mechanized and automatized : feeding yarn, joining ends, winding and cutting threads, and removing product. Automatic control is also widely used in finishing; but much scope yet remains. A few solution strengths are controlled: sulphuric acid, sodium hydroxide and hypochlorite; but there is no suitable automatio control of moisture content of fabric after drying. In printing, too, the superposing of different coloured patterns in multi-colour work, along with other operations, should be automatized. Continuous antomatic lines with cascade electric drives should be developed, providing the required range of speeds and automatic control of tensions.

The problems are widely different in tanning. Here there may be forty to fifty operations, of which up to 60 per cent may be mechanized in the best Soviet factories. With the aid of conveyors, cranes, telpher lines, automatic loaders, etc., mechanization at least (automatic or not) could be raised to 90 per cent. Suggestions for automatic continuous production lines have already been put forward by inventors and innovators, with a series of mechanized units of a new kind. Measuring devices, automatic controls of humidity, of dyeing, drying, spraying and fixing have yet to be perfected.

The author proceeds to discuss the progress made in some of the food industries, where automatism is in various stages. During the past few years, breadmaking has been highly mechanized; but automatic controls are still lacking in respect of moisture content of dough, temperature and moisture in the ovens, level of dough in the kneaders, and in other directions. In the confectionery trades much also yet remains to be done, although it is claimed that an automatic device has been evolved for caramels, with pressure and temperature control, and with automatic discharge periodically during continuous operation of the vacuum cooker. 
In dairy work, although mechanization is said to have reached an advanced stage, from which the transition to almost complete automation should be relatively easy, this has not been accomplished. The so-called Meleshin method of making butter is eited as an exception; the process is said to have many features of interest, though none of these is described. The production cycle-time is reduced from $20 \mathrm{hr}$. to $40 \mathrm{~min}$; ; the butter is of high quality and keeps well in storage. It ought not to be difficult to extend automation generally throughout the dairy and allied industries, at all events so far as concerns the control of fat, sugar and other ingredient contents.

In the oils and fats industry, modern plant has been more extensively adopted, including continuous instead of batch operation both in production of the oil and in its refining. Some progress is reported in the matter of automation, but methods are still imperfect in respect of controls for certain operations : determinations of oil and moisture content, automatic weighings and feeds. Reference is made to new devices for automatic quality-control of products and of filter-press operation based in some way on dielectric losses; but no details are given. W. G. CAss

\section{BASIC RESEARCH IN THE UNITED STATES}

$\mathrm{T}$

HE concern which is felt in the United. States over the increasing dependence of basic research upon Government support is reflected in three papers contributed to a symposium on the roles of Government, industry and the university in basic research. The symposium was held in Berkeley, California, on December 30,1954 , and the papers have now been published in Science $(121,781 ; 1955)$. Discussing the role of Government, P. E. Klopsteg, of the National Science Foundation, defines basic research as the systematic endeavour, without preconception, to increase our knowledge and understanding of Nature, and he suggests that, if this definition could be applied precisely, the Government funds given for this purpose, estimated at 116 million dollars, 120 million and 131 million dollars for 1953, 1954 and 1955, respectively, would be drastically revised downwards. Nevertheless, the Government contribution is now many times greater than before the Second World War, and without discussing all the implications of such dependence on Government support, apart from the possibility of an ultimate deterioration in the quality of research and of bureaucratic interference with the administration of institutions of higher learning, Mr. Klopsteg thinks that Government policy should seek to encourage greater support of basic research both by corporations and individuals. For this he suggests that the income-tax law pertaining to charitable donations should be revised so as to encourage donations by taxpayers to basic research by one of three methods outlined which provide strong incentives for giving.

While the Government would still have an important responsibility for the direct support of research in its own laboratories and for the support of such research at educational institutions and of large projects by team research, Mr. Klopsteg considers that the proposals he makes would check the trend towards almost exclusive dependence on Government support. Institutions would derive their major support from private donors and corporations.
Research would be kept free, and the severity of many problems originating in the inadequacy of funds for higher education would be reduced.

Mr. M. E. Speght, of the Shell Oil Co., New York, discussing basic research in industry, gives the number of research workers in the United States as 450,000 , of whom more than a third have a bachelor's degree. Expenditure on industrial research laboratories is put at 2,500 million dollars, of which 1,100 comes from Government sources, and about 150,000 persons are employed in such work. Taking the total man-power, research costs are estimated at 7,000-10,000 dollars a year; but for professional workers the medium costs are about 15,000-25,000 dollars a year. Defining basic research as seientific inquiry carried on, not under pressure of immediate needs or in hope of quick profit, but with reasonable hope of some eventual payment, Mr. Speght estimates that industry employs some ten thousand people, four thousand of whom are professionals, and spends a hundred million dollars a year on such work, of which about ten million dollars is in support of research in universities and other non-profit institutions. The limits on basic research are most likely to be set by the number of worth-while ideas that the scientific worker of the organization can propose; but Mr. Speght agreed that a greater investment in the search for new knowledge is necessary if the present rate of technological advance is to continue. He also believes that industry's contribution, particularly to universities and their affiliated research institutes, will continue to increase, and he does not think that this trend can be interrupted by a business recession.

Discussing the role of the university, Prof. K. S. Pitzer recognized the inadequacy of university budgets in the United States even for the present level of basic research, and welcomed the effect of all Government aid to research. The administration of Government funds for this purpose by various Government agencies has been excellent; but he criticized the practice of breaking down the funds into very small units tied closely to particular projects. Funds made available to the universities on a broad basis are used very much more effectively, and he thought that both Government and industry could contribute to improved methods in the future.

\section{GRANTS TO STUDENTS IN TRAINING COLLEGES IN BRITAIN}

\section{THE Working Party on Grants to Training} College Students, on the recommendations of which the increased grants recently announced by the Minister of Education are based, was appointed in January 1954, with Mr. A. E. Miles Davies as chairman, to work out the costs which students at training colleges in Great Britain are called upon to meet and which are known to vary substantially and merit examination; the amount which parents or students should be required to contribute; the distribution of the balance over all local education authorities; and the reduction of the range of "incidental expenses". The then Minister of Education, Miss (now Dame) Florence Horsbrugh, in appointing the Committee, made it clear that she could not entertain any suggestion for relieving local education authorities of their present responsibility for sharing this expenditure with the Exchequer in 